\title{
Dynamic Operation and Control of a Stand-Alone Wind/PV/Diesel Energy Systems
}

\author{
Cong-Hui Huang ${ }^{1}$ Chih-Ming Hong ${ }^{2}$ Chung-Chi Huang ${ }^{1}$ Jheng-Han Lin ${ }^{3}$ Bo-Yan Shi ${ }^{1}$ Chuan-Sing Jhuang ${ }^{1}$ \\ ${ }^{1}$ Automation and Control Engineering, Far East University \\ ${ }^{2}$ Electronic Communication Engineering, National Kaohsiung Marine University \\ ${ }^{3}$ Mechanical Engineering, Far East University
}

\begin{abstract}
This paper presents the dynamic operation and control strategies of a hybrid wind/photovoltaic/diesel based power supply system for stand-alone applications. Wind and PV power are the primary power sources of the system to take full advantages of renewable energy, and the diesel-engine is used as a backup system. To achieve a fast and stable response for the real power control, the intelligent controller consists of a Radial Basis Function Network and an modified Elman Neural Network for maximum power point tracking.

Keywords ${ }^{-}$photovoltaic power system, wind power system, radial basis function network, modified Elman neural network, maximum power point tracking, diesel-engine.
\end{abstract}

\section{Introduction}

Wind and solar power generation are two of the most promising renewable power generation technologies. Variable-speed wind turbines have many advantages that are well documented in the literature [1-2]. The wind turbine can operate with maximum aerodynamic efficiency, and the power fluctuations can be absorbed as an inertial energy in the blades. In some applications, the wind turbine may be augmented by an additional power source, usually a diesel generator. These systems are called wind-diesel systems [3-4] and may be used to supply electricity energy to stand-alone loads, e.g., small villages that are not connected to the main utility. Variable-speed operation can increase the efficiency, where the fuel consumption can be reduced up to $40 \%$ [5], especially when operating with a light load. Moreover, the life expectancy can increase with a lower thermal signature. To avoid the frequent start/stop of the diesel generator, an energy storage system is often used.

Topologies of the power electronic converter for Maximum Power Point Tracking (MPPT) [6] and voltage conversion are studied in this paper. The maximum power point of photovoltaic array is variational, so a search algorithm is needed according to the currentvoltage $(\mathrm{I}-\mathrm{V})$ and power-voltage $(\mathrm{P}-\mathrm{V})$ characteristics of the solar cell. By using $\mathrm{P} \& \mathrm{O}$ method, impedance matching is conducted between boost converter and photovoltaic array in order to realize the MPPT function [7-8].

The receptive field functions of the RBFN are also similar to the membership functions of the premise part of the fuzzy-logic system. With advantages of multiple facets and the self adapting capabilities, RBFN is very useful for controlling nonlinear and time-varying dynamic systems where uncertainties and parameter variations need extra attention [9].

\section{Analysis of System Overview}

The proposed PV and diesel-wind hybrid system is shown in Fig. 1. Dynamic models of the main components were developed using
MATLAB/ Simulink, consisting of 1) $\square$ wind energy conversion system, 2) diesel generator system, 3) $\square$ PV generation system.

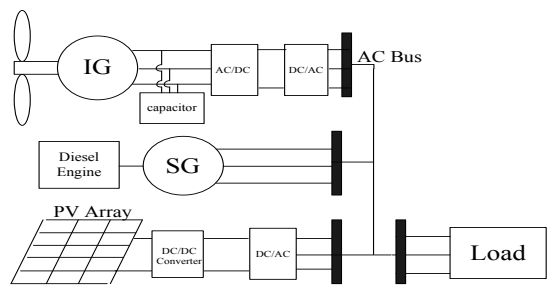

Fig. 1 The proposed hybrid system.

In order to capture the maximal wind energy, it is necessary to install the power electronic devices between the WTG and the grid where the frequency is constant. The input of a wind turbine is the wind and the output is the mechanical power turning the generator rotor [6]. For a variable speed wind turbine, the output mechanical power available from a wind turbine could be expressed as

$$
P_{m}=\frac{1}{2} \rho A C_{p}(\lambda, \beta) V_{\omega}^{3}
$$

where $\rho$ and $\mathrm{A}$ are air density and the area swept by blades, respectively. $V_{\omega}$ is the wind velocity $(\mathrm{m} / \mathrm{sec})$, and $C_{p}$ is called the power coefficient, and is given as a nonlinear function of the tip speed ratio (TSR) $\lambda$ with

$$
\lambda=\frac{\omega_{r} r}{V_{\omega}}
$$

where $r$ is wind turbine blade radius, and $\omega_{\mathrm{r}}$ is the turbine speed. $C_{p}$ is a function of $\lambda$ and the blade pitch angle $\beta$.

\section{MPPT Control Algorithm of PV System}

With the cost of PV cell, it is necessary to implement MPPT to have the voltage operating close to the maximum power point under the changing environment. The proposed PV system is composed of an array of $4 \times 4$ panels, a dc/dc converter, a battery storage, dc/ac inverter and a control algorithm, generally performed by a microcontroller to track the maximum power continuously. MPPT is also used to provide a constant voltage to the required load.

\subsection{Perturbation and Observation Method}

The most common method in this field is the P\&O method [10]. It periodically increases or decreases the PV cell's voltage as mentioned before to seek the maximum power point. In this paper, a variable step method is proposed to search for the maximum power 
point, where the step lengths is adjusted according to the distances to the MPP. The ratio of the variation of power $(P)$ to voltage $(V)$ is considered as the step length of duty ratio $D$, which is actually the slope of each operating point under very short sampling time. Fig. 2 shows the control block of the P\&O method.

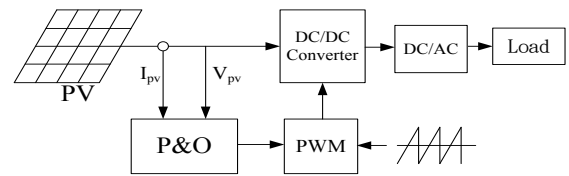

Fig. 2 Configuration of the $\mathrm{P} \& \mathrm{O}$ control system

\subsection{RBFN Controller Design}

Once the IENN is initialized, a supervised learning is used to $\mathrm{A}$ three-layer RBFN neural network with a boost converter shown in Fig. 3 is adopted to implement the controller [11-12] where the control law $V_{M P P T}$ is generated. In the proposed RBFN, the number of units in the input, hidden, and output layers are three, nine and one, respectively. In order to apply RBFN control, PV system in Fig. 4 is linearized in this section. The PWM module is used to generate PWM pulses to control the duty cycle of the switch.

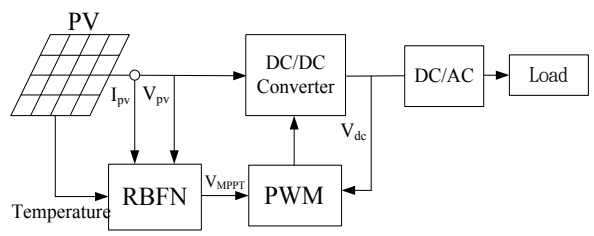

Fig. 3 Configuration of the RBFN control system

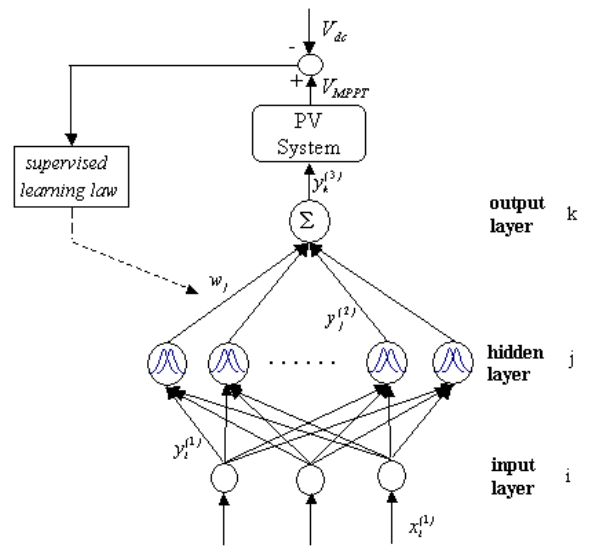

Fig. 4 Structure of the three-layer RBFN

\section{Simulation Results}

\subsection{Wind power MPPT}

Time domain simulation was run for the hybrid power system with constant load under sufficient wind and irradiance. The output power from WECS is shown in Fig. 5. From Fig. 5, it can be seen that the ENN controller provides a better control performance than PI with less transient and smaller vibrations. The transient response of the design at the start point can be seen clearly that PI fluctuate much more, but ENN oscillates only slightly. The average power is
$1.88 \mathrm{KW}$. Compared with that of the PI control, it increases by $6.2 \%$. With different wind speeds, the performance comparison is shown in Table I.

\subsection{PV Power MPPT}

The output power from PV is shown in Fig. 6. From Fig. 6, we can see that the RBFN controller provides a better performance than $\mathrm{P} \& \mathrm{O}$, both in the transient and the stability. The average power is $2.7 \mathrm{KW}$. Compared with that of $\mathrm{P} \& \mathrm{O}$, it increases by $14.89 \%$. The RBFN method can quickly and accurately track the maximum power output for PV array.

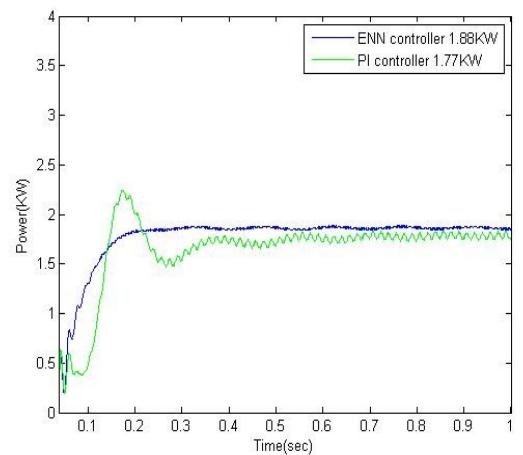

Fig. 5 Maximum power tracking response of the WECS

TABLE I. Performance comparison of ENN and PI controller

\begin{tabular}{|c|c|c|c|c|}
\hline $\begin{array}{c}\text { Controller } \\
\text { Type }\end{array}$ & $\begin{array}{c}\text { Wind } \\
\text { speed }\end{array}$ & $\begin{array}{c}\text { Power } \\
\text { Coefficient } \\
\text { (Cp) }\end{array}$ & $\begin{array}{c}\text { Pitch } \\
\text { angle } \\
\text { (degree) }\end{array}$ & $\begin{array}{c}\text { Average } \\
\text { power } \\
(\mathrm{KW})\end{array}$ \\
\hline \multirow{2}{*}{$\mathrm{ENN}$} & $12 \mathrm{~m} / \mathrm{s}$ & 0.482 & -0.07 & 1.88 \\
\cline { 2 - 5 } & $8 \mathrm{~m} / \mathrm{s}$ & 0.481 & -0.08 & 0.22 \\
\hline $\mathrm{PI}$ & $12 \mathrm{~m} / \mathrm{s}$ & 0.465 & -0.55 & 1.77 \\
\hline
\end{tabular}

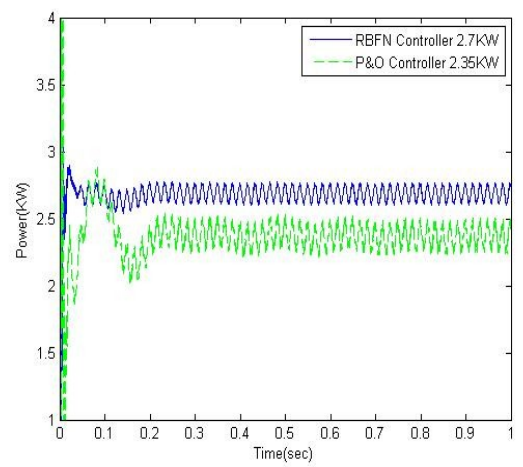

Fig. 6 Power response of the PV system

\section{Conclusion}

In this paper, a PV and diesel-wind hybrid generation system was proposed and implemented. This stand-alone hybrid generation system can effectively extract the maximum power from the wind and PV energy sources. From the case studies, it shows that voltage and power can be well controlled in the hybrid system under a changing 
environment. An efficient power sharing technique among energy sources are successfully demonstrated with more efficiency, a better transient and more stability, even under disturbance.

The simulation model of the hybrid system was developed using MATLAB/Simulink. The load frequency is regulated by the diesel generator by imposing the rotor currents with the slip frequency. The electrical torque of the WECS generator is controlled to drive the system to the rotational speed where maximum energy can be captured. Depending on the load size and the power supplied by the WECS generator, the control system regulates the DGS rotational speed to minimize the fuel consumption.

\section{References}

[1] G. Abad, M. A. Rodriguez, G. Iwanski, and J. Poza, "Direct power control of doubly-fed-induction-generator-based wind turbine under unbalanced grid voltage," IEEE Trans. Power Electron., vol. 25, no. 2, pp. 442-452, Feb. 2010.

[2] S. M. B. Wilmshurst, "Control strategies for wind turbines," Wind Eng., vol. 12, pp. 236-249, Jul. 1988.

[3] A. J. Rudell, J. A. M. Bleijs, L. Freris, D. G. Infield, and G. A. Smith, "A wind diesel system with variable speed flywheel storage," Wind Eng., vol. 17, pp. 129-145, May 1993.

[4] R. Dettmer, "Revolutionary energy - A wind/diesel generator with flywheel storage," Inst. Electr. Eng. Rev., vol. 36, pp. 149-151, Apr. 1990.
[5] Z. Chen, and Y. Hu, "A hybrid generation system using variable speed wind turbines and diesel units," in Proc. IEEE Ind. Electron. Soc. Annu. Meeting Conf., 2003, pp. 2729-2734.

[6] B. S. Borowy, and Z. M. Salameh, "Dynamic response to a stand-alone wind energy conversion system with battery energy storage to a wind gust," IEEE Trans. Energy Convers., vol. 12, no. 1, pp. 73-78, Mar. 1997.

[7] N. Femia, G. Petrone, G. Spagnuolo, and M. Vitelli, "Optimization of perturb and observe maximum power point tracking method," IEEE Trans. Power Electron., vol. 20, no. 4, pp. 963-739, July 2005.

[8] B. Yang, Y. Zhao, and X. He, "Design and analysis of a gridconnected photovoltaic power system," IEEE Trans. Power Electron., vol. 25, no. 4, pp. 992-1000, April 2010.

[9] S. Seshagiri, and H.K. Khail, "Output feedback control of nonlinear systems using RBF neural networks," IEEE Trans. Neural Netw., vo1. 11, pp. 69-79, 2000.

[10] D. Das et al., "An optimal design of a grid connected hybrid wind/photovoltaic/fuel cell system for distributed energy production," in Proc. 32nd Annu. Conf. IECON, Nov. 6-10, 2005, pp. 2499-2504.

[11] C. T. Lin, and C.S. George Lee, "Neural fuzzy systems", Prentice-Hall, Inc., 1996.

[12] S. Wan, H. Li, and Y. Li, "Adaptive radial basis function network and Its application in turbine-generator vibration fault diagnosis," in Proc. Power System Technology Conf., 2002, vo1. 3, pp. 1607-1610. 